\title{
Sociosexual behaviour and paternity in procarbazine-exposed rats with or without regional testicular circulatory isolation
}

\author{
S. A. Farr ${ }^{1,2,3}$, F. E. Johnson ${ }^{1,3 *}$ and G. T. Taylor ${ }^{2}$ \\ ${ }^{1}$ Department of Surgery, St Louis University Medical School, St Louis, MO 63110-0250, USA; \\ ${ }^{2}$ Behavioral Neuroscience Laboratory, University of Missouri, St Louis, MO 63121, USA; and \\ ${ }^{3}$ Department of Veterans Affairs, St Louis Medical Center, St Louis, MO 63106, USA
}

\begin{abstract}
Male Sprague-Dawley rats were used in two experiments in which a procarbazine bolus (400 $\mathrm{mg} \mathrm{kg}^{-1}$ body mass) was administered with or without testicular circulatory isolation in the form of brief clamping of the spermatic cord and gubernaculum during drug administration. Separate tests of aggressiveness, sexual motivation, copulatory performance and paternity over the subsequent 6 weeks were used to assess functional changes resulting from testicular circulatory isolation. Experiment I compared intermale aggression and sexual motivation of animals in groups receiving procarbazine plus testicular circulatory isolation lasting 0,15 or $45 \mathrm{~min}$ with that of animals in control groups with no clamp and no drug. Experiment 2 used a $2 \times 2$ factorial design to evaluate sexual performance and resulting paternity in animals 2 months after testicular circulatory isolation and drug exposure compared with that in control animals. Procarbazine treatment induced minimal disruption of normal interest in a receptive female, copulatory measures (intromissions or ejaculations) and structural integrity of seminal vesicles, bulbospongiosus muscles and ventral prostate glands. Animals exposed to the drug without testicular circulatory isolation were significantly less aggressive than animals in other groups. The most profound influence of procarbazine was on paternity. Males exposed to procarbazine with or without testicular circulatory isolation impregnated notably fewer females than did control males that were not exposed to the drug. There was no evidence of recovery of normal fertility up to 10 weeks after exposure to the drug. In conclusion, the deleterious influence of procarbazine on androgen-sensitive processes appears to be specific to intermale aggression and to fertility. The testicular circulatory isolation technique, for $45 \mathrm{~min}$ in particular, softened the impact of the drug on social behaviour, although procarbazine suppressed fecundity even with testicular circulatory isolation.
\end{abstract}

\section{Introduction}

A primary concern in cancer treatment is long-term dysfunction in organs other than the target of chemotherapy. Procarbazine is commonly used in multi-agent regimens, particularly against lymphomas. The acute toxicity of procarbazine on bone marrow and the gastrointestinal tract usually recovers with time. Unfortunately, the acute gonadal toxicity is usually irreversible (Schilsky et al., 1980; Byrne et al., 1987; Rivkees and Crawford, 1988). Therefore, it is of considerable clinical interest to develop procedures that reduce the initial testicular injury (Ward et al., 1990; Kangasniemi et al., 1995a). Surgical procedures involving short-term regional vascular isolation offer a potential solution. Techniques using tourniquets and occlusive intra-aortic balloons to provide regional organ protection by partial vascular occlusion have been reported (Conrad and Crosby, 1960; Gregory et al., 1982;

*Reprint requests.

Revised manuscript received 7 February 1997. van Vliet et al., 1988). The procedure is to isolate a vulnerable organ system from the systemic circulation for the duration of the half-life of the drug or longer.

We have reported (Farr et al., 1993) an animal model of testicular circulatory isolation (TCI), applied for the duration of the half-life of a typical chemotherapeutic drug. An arterial clamp is applied to the spermatic cord and gubernaculum immediately before injection of procarbazine, and then removed up to $45 \mathrm{~min}$ later. Our prior findings (Stern et al., 1990; Farr et al., 1993) suggested that TCI may provide at least partial testicular protection during chemotherapy, as measured by morphology and function of testes in rats exposed to procarbazine with or without $\mathrm{TCl}$. Although the number of testicular spermatozoa may not return completely to control values, the concentration of spermatozoa in procarbazineexposed rats with TCI may be enough to impregnate a female. Indeed, there are data pointing to successful paternity in some males that were given an unlimited time with the female (Liebscher et al., 1990), although no attempt was made to assess how 'normal' the sexual responses of the treated males were. 
The present study used the TCI animal model to answer two questions of considerable clinical interest. (1) What are the patterns of initial and eventual disruption of androgen-sensitive sociosexual behaviour due to procarbazine administration? (2) Can TCI protect against acute and chronic behavioural dysfunction and promote full recovery following procarbazine treatment of the varied reproductive systems contributing to normal fertility?

Young adult male rats were used in two experiments using well-established paradigms for quantifying rodent social behaviour (Barfield, 1993; Taylor et al., 1993; Sachs and Meisel, 1994). Experiment 1 was used to track changes in sexual motivation and aggressive behaviour for 8 weeks after procarbazine was administered with or without TCI. Experiment 2 assessed copulatory performance and the capacity of males to impregnate females 2 months after procarbazine treatment with or without TCI. At necropsy, prostate glands, seminal vesicles and bulbospongiosus muscles were examined as morphological markers of normal androgenic activity.

\section{Materials and Methods}

\section{Animals and housing}

The animals were sexually naive Sprague-Dawley male rats ( $n=80,9$ weeks old, Harlan Sprague-Dawley, Indianapolis, IN) at the beginning of experimentation. Animals were housed individually in hanging plastic cages measuring $48 \mathrm{~cm} \times$ $24 \mathrm{~cm} \times 20 \mathrm{~cm}$. In addition, females $(n=50)$ and another set of males $(n=10)$ of the same age, strain and source as the experimental males were used as 'stimulus animals' for the behaviour tests. Standard rat chow and tap water were available ad libitum throughout the experiments. Temperature $\left(21^{\circ} \pm 1^{\circ} \mathrm{C}\right)$ and relative humidity $(50 \%)$ were controlled automatically. Lighting was on a cycle of $12 \mathrm{~h}$ light and $12 \mathrm{~h}$ darkness each day.

\section{Materials}

Apparatus. For behavioural observations, a metal and Plexiglas apparatus measuring $120 \mathrm{~cm} \times 30 \mathrm{~cm} \times 30 \mathrm{~cm}$, with wire mesh flooring, was constructed based on a terrarium described in detail by Taylor et al. (1993). The only difference was the designation of a section $16 \mathrm{~cm}$ wide in the middle of the apparatus as a neutral space to provide a clear distinction between left and right sides of the apparatus. As in the previous study (Farr et al., 1993), a Doppler flow detector (Model 812, Parks Medical Electronics, Aloha, OR) was used during surgery to confirm successful interruption of blood flow with the non-traumatic vascular clamps.

Drugs. Procarbazine hydrochloride was donated by Hoffman-LaRoche (Nutley, NJ) and freshly prepared for each administration by dissolution in $0.9 \%(\mathrm{w} / \mathrm{v}) \mathrm{NaCl}$. Oestrogen and progesterone were purchased from Sigma Chemical Co. (St Louis, MO) and suspended in olive oil for injection. The hormones were used to induce behavioural oestrus in ovariectomized females.

\section{Surgery}

Surgical procedures for $\mathrm{TCl}$, as well as methods for administering anaesthesia (pentobarbital sodium) and drug (procarbazine or placebo), have been described in detail by Farr et al. (1993). Essentially, intravenous access was via internal jugular vein cutdown. TCI was accomplished by applying non-traumatic vascular clamps to the surgically exposed spermatic cord and gubernaculum. Clamps were removed after either $15 \mathrm{~min}$ or $45 \mathrm{~min}$. Cessation and return of blood flow was confirmed by the Doppler flowmeter. Controls and drugexposed males without TCI received sham surgery, during which the testis was exposed and returned to the scrotum using the same technique as for the $\mathrm{TCI}$ groups, but without clamping.

Females for Expt I were ovariectomized using a single abdominal incision (Taylor et al., 1989a). Uterine horns were exposed and ovaries were excised. All incisions were closed with 3-0 polyglycolic acid suture.

\section{Experimental design}

Males $(n=40)$ for Expt 1 were assigned at random to one of four groups ( $n=10$ per group). Experimental animals (groups 2-4) received a single bolus of procarbazine ( $N$-(Imethylethyl)-4-[(2-methylhydrazino)methyl]benzamide monohydrochloride) via a jugular vein injection (400 $\mathrm{mg} \mathrm{kg}^{-1}$ ) and, simultaneously, received the $\mathrm{TCI}$ procedure for either $15 \mathrm{~min}$ (group 2) or 45 min (group 3). The other experimental group (group 4) received drug without TCI. Group 1 controls received neither treatment. Because the influence of $\mathrm{TCl}$ alone has been the subject of previous studies from this laboratory (Stern et. al, 1990), a control group receiving TCI but no drug was not included in the first experiment. Animals were left undisturbed for two weeks after surgery, and behavioural tests began during week 3 and continued into week 10 .

A $2 \times 2$ factorial design ( $n=10$ per group) was used in Expt 2 with the main factors consisting of drug exposure (procarbazine or placebo) and manipulation (TCl or no TCI). Group 1 received sham surgery without either procarbazine or TCI, group 2 received TCI for $45 \mathrm{~min}$ without procarbazine, group 3 received procarbazine plus TCI for $45 \mathrm{~min}$, and group 4 received sham surgery with procarbazine. Tests of fertility began after 2 months; during this time the animals were left undisturbed to allow the required period for new spermatogenesis in male rats (Clermont, 1972). Behavioural observations were conducted during each of two fertility tests separated by 2 weeks.

Behavioural methods and necropsies performed at the end of the two studies were procedures that we have used frequently over the past decade. A brief description for each method of data collection follows.

\section{Procedural details}

Pre-experimental experiences. Subject males were exposed to a sexually receptive female before the beginning of the experiment. An ovariectomized female was induced to oestrus with s.c. injections of $100 \mu \mathrm{g}$ oestradiol benzoate and, $48 \mathrm{~h}$ later, $400 \mu \mathrm{g}$ progesterone $3-4 \mathrm{~h}$ before being placed 
overnight in the home cage of the male (Taylor et al., 1989a). Neither formal observations of successful copulation nor other evidence, such as the presence of a copulatory plug in the animal's bedding (Sachs and Meisel, 1994), were obtained during this pre-experimental period. However, informal observation suggested that most males copulated during the $12 \mathrm{~h}$ that each male spent with a female in oestrus.

Experiment 1: sexual motivation and intermale aggression. In the third week after surgery, behavioural testing started and continued for the next 6 weeks. Stimulus animals for the two social behaviour paradigms were ovariectomized females $(n=10)$ and untreated adult males (also $n=10$ ). Every male was observed once each week. Aggression test sessions with an unfamiliar stimulus male were conducted on 3 weeks and tests of sexual motivation with an ovariectomized female were conducted on the other 3 weeks (Taylor et al., 1994). Observations were conducted in an experimental room away from colony rooms. After each session, the apparatus was cleaned thoroughly with soap and water.

Scheduling of sessions was counterbalanced within and between groups. Stimulus animals were, by necessity, paired with several subject males during the 3 weeks of behavioural testing. However, care was taken that the same subject and stimulus animal were not paired more than once. Moreover, neither a subject male nor a stimulus animal was tested twice on the same day. Behavioural observations continued until the end of the study, when all subject males were killed.

Experiment 2: copulatory behaviour and paternity. Vaginal smears were used to monitor stages of the oestrous cycle of the unoperated, cyclic females $(n=40)$ used for paternity testing beginning 2 months after treatment. With colony lights off at 10:00 h, testing was conducted during the initial $4 \mathrm{~h}$ of darkness and in the home cages of the males. A female detected to be in late pro-oestrus to early oestrus was introduced into a male's home cage for a mating session lasting $60 \mathrm{~min}$. Measures of sexual performance were recorded for the pair. After the session was completed, the female was returned to her individual home cage to await parturition.

The procedure described by Taylor and Weiss (1987) was used to allow each male two opportunities to impregnate a female. If the female from the first mating session clearly was not pregnant, the male was given a second mating test with a different receptive female 2 weeks after the initial session; that is, only those males failing to impregnate a female during the initial $60 \mathrm{~min}$ session were given a second opportunity to impregnate another female.

\section{Behavioural measures}

Sexual motivation was evaluated apart from sexual performance. Our test of sexual motivation used a well-established paradigm (Taylor et al., 1994) for evaluating the probability of actively searching for a receptive female. Ovariectomized females were housed in small wire cages at opposite ends of an apparatus. One of the females was induced to receptivity by hormone injections; the other female was not injected. The male could move freely about the apparatus without direct interactions with the females that confound assessment of the interest of the male in making social contact. Motivation was quantified by the relative time the male spent near the inaccessible oestrous female as opposed to the non-oestrous female during test sessions lasting $20 \mathrm{~min}$.

Aggressive behaviour was evaluated (Taylor et al., 1996) in a terrarium during $10 \mathrm{~min}$ sessions once a week between a subject male and an untreated, unfamiliar male. The two animals were introduced into the terrarium simultaneously to avoid resident-intruder complexities. Frequencies of categories of aggression in male rats described by Grant (1963) were recorded and totalled for an aggression score for each pair (Taylor et al., 1984). Each incidence of pushing, sideways kicking, aggressive grooming, aggressive posturing and attack with biting observed by the single experimenter was tallied.

Sexual performance was assessed (Taylor et al., 1989b) in Expt 2 during pairings of a male with a gonadally intact female detected as being receptive by a vaginal smear. An oestrous female was placed into the home cage of the male for the mating test. Latencies to first intromission and frequencies of both intromissions and ejaculations were recorded during a 60 min session. Frequencies of female solicitations of the male and her rejections of his sexual approaches were also measured (Taylor et al., 1989a).

\section{Fertility}

Paternity was established in the second experiment by delivery of live pups from female partners of the males. Tightly constrained mating sessions of $60 \mathrm{~min}$ were used as a limiting condition for the expression of fertility. A male was given two opportunities to impregnate different receptive females. Males were given a paternity score according to whether a female was impregnated during the initial sexual contact (score of 2), the second session (score of 1 ) or neither (score of 0 ). Numbers of pups per litter were recorded, and the entire litter was weighed.

\section{Physiological measures}

Sex accessory organs representing targets of androgens were examined at necropsy. We used multiple markers of the reproductive system to estimate disruption of normal function (Taylor $e$ t al., 1989b, 1996). Seminal vesicles, bulbospongiosus muscles and ventral prostate glands were excised and examined for indications of pathology. Wet masses were recorded for each structure. Sperm head counts and testicular integrity were not measured in this study since these measurements were made from similar groups of animals during previous work (Stern et al., 1990; Farr et al., 1993).

\section{Statistical analyses}

Data from Expt I obtained during the weekly tests of sexual motivation and aggression were examined with analyses of variance (ANOVA). Repeated measures factorial ANOVAs, with time as the repeated factor, were performed on data from Expt 1 as a measure of recovery following experimental treatment. Tukey's honestly significant difference tests (HSD) 
Table 1. Scores (means $\pm \mathrm{SEM}$ ) of sexual motivation and intermale aggression in male rats $(n=10$ per group) of Experiment $I$ treated with or without $400 \mathrm{mg}$ procarbazine $\mathrm{kg}^{-1}$ and testicular circulatory isolation (TCI)

\begin{tabular}{|c|c|c|c|c|c|}
\hline \multirow[b]{2}{*}{ Group } & \multicolumn{2}{|c|}{ Sexual behaviour } & \multicolumn{3}{|c|}{ Reproductive physiology } \\
\hline & $\begin{array}{l}\text { Sexual } \\
\text { motivation } \\
\text { score }\end{array}$ & $\begin{array}{l}\text { Intermale } \\
\text { aggression } \\
\text { score }\end{array}$ & $\begin{array}{l}\text { Seminal } \\
\text { vesicles } \\
(\mathrm{mg})\end{array}$ & $\begin{array}{l}\text { Ventral } \\
\text { prostate } \\
\text { glands } \\
(\mathrm{mg})\end{array}$ & $\begin{array}{l}\text { Bulbospongiosus } \\
\text { muscles } \\
\text { (mg) }\end{array}$ \\
\hline 1 (Control: no drug, no clamp) & $12.1 \pm 0.3$ & $171 \pm 13^{\mathrm{a}}$ & $37 \pm 3$ & $21 \pm 2$ & $26 \pm 1$ \\
\hline $2($ Drug $+\mathrm{TCI}$ for $15 \mathrm{~min})$ & $11.9 \pm 0.4$ & $132 \pm 14^{\mathrm{bc}}$ & $35 \pm 2$ & $19 \pm 1$ & $26 \pm 1$ \\
\hline 3 (Drug $+\mathrm{TCl}$ for $45 \mathrm{~min}$ ) & $11.8 \pm 0.2$ & $161 \pm 8.5^{\mathrm{ab}}$ & $37 \pm 3$ & $20 \pm 1$ & $25 \pm 1$ \\
\hline 4 (Drug, no clamp) & $11.9 \pm 0.4$ & $115 \pm 9.0^{c}$ & $34 \pm 2$ & $18 \pm 2$ & $26 \pm 1$ \\
\hline
\end{tabular}

Sexual motivation was scored as the relative time (in min) that the male rat spent near an inaccessible oestrous female as opposed to a non-oestrous female during a 20 min test session (Taylor et al., 1994).

Intermale aggression was scored according to frequencies of categories of aggression in male rats described by Grant (1963) and totalled as described by Taylor et al. (1994).

Androgen-sensitive structures (seminal vesicles, ventral prostate glands and bulbospongiosus muscles) were weighed 10 weeks after treatment ( $\mathrm{mg}$ tissue per $100 \mathrm{~g}$ body mass).

Only the measure of aggression achieved statistical significance; the superscript letters indicate statistically reliable groups (according to Tukey's HSD test; $P<0.05$ ) (that is, letters that differ denote groups that differed significantly).

were used for post-hoc, pair-wise comparisons of mean group differences. Statistical significance was set at $P<0.05$ in each case.

Frequencies of types of behaviour and masses of tissues from Expt 2 were analysed by $2 \times 2$ factorial analyses of variance (ANOVA; $P<0.05$ ), the main factors being drug (exposed to procarbazine or not) and TCI (either TCI for $45 \mathrm{~min}$ or not). The behavioural scores analysed were either the totals for the session for those males requiring a single session to impregnate a female or a mean average for the animals requiring two sessions of sexual contact. Finally, paternity scores reflecting whether the male impregnated a female on the first, second or neither attempt were analysed.

\section{Results}

Findings from the aggression tests with stimulus males and tests for interest in inaccessible oestrous females were summarized and are reported as group means \pm SEM (Table 1 ). Females delivering pups from each group were converted to percentage values; that is, the percentages reported in Table 2 are the number of males per group that successfully impregnated a female in either of two mating sessions.

\section{Experiment 1: sexual motivation and intermale aggression}

There were no significant differences among main factors or the interactions for the motivation measure. The conclusion is that groups did not differ in the time spent in proximity to an oestrous as opposed to a non-oestrous female, the measure of sexual interest used here.

The repeated measure analyses of aggressive behaviour yielded non-significant values for the 'week of testing' main effect and for the group $\times$ weeks interaction. Those findings indicate that aggressive responding did not change during the weeks of testing for any of the groups. However, the value obtained for the 'group' main factor for aggressive behaviour was statistically reliable $\left[F_{(3.36)}=5.17, P<0.05\right]$. Post-hoc analyses to detect which groups differed revealed that the procarbazine-exposed males without $\mathrm{TCI}$ were the least aggressive animals in the entire study, whereas the control group without drug or clamp and the group with drug and TCI for $45 \mathrm{~min}$ were most aggressive.

\section{Experiment 2: sexual performance and paternity}

In this paradigm, the males were allowed to interact actively with receptive females in mating tests given during weeks 8-10 after experimental treatments. There were no significant differences for the drug or the TCI main effects or for their interaction on either measures of sexual performance (copulatory intromissions and ejaculations). On the other hand, there were clear decreases in paternity due to drug treatment. Experimental and control groups were compared on a paternity score based on whether a female delivered live pups after the first, second or neither mating test. It is notable that $40 \%$ of the group without the drug or TCI failed to impregnate a female. This probably reflects the strict conditions imposed by our paradigm to limit time for mating.

Nonetheless, results of the analyses of females with live births revealed significant differences only with respect to the main factor of drug $\left[F_{(1,36)}=6.97, P<0.05\right]$; that is, groups exposed to procarbazine were significantly less successful in impregnating females than the two groups not exposed to procarbazine. There were no significant differences between the two drug-exposed groups. In addition, the two groups without drug did not differ. Indeed, the group without drug but with $\mathrm{TCl}$ and the group without either drug or TCI fathered similar numbers of pups per litter (means $=11.0$ and 12.6, respectively) and the body masses of the pups were similar (means per pup $=6.8 \mathrm{~g}$ and $6.2 \mathrm{~g}$, respectively). 
Table 2. Scores (means \pm SEM) of sexual performance and paternity of male rats ( $n=10$ per group) of Experiment 2 treated with $400 \mathrm{mg}$ procarbazine $\mathrm{kg}^{-1}$ or placebo with or without testicular circulatory isolation $(\mathrm{TCI})$

\begin{tabular}{|c|c|c|c|c|c|c|}
\hline \multirow[b]{2}{*}{ Group } & \multicolumn{2}{|c|}{ Sexual performance } & \multicolumn{3}{|c|}{ Reproductive physiology } & \multirow{2}{*}{$\begin{array}{c}\text { Paternity } \\
\text { Percentage } \\
\text { number of } \\
\text { males fathering } \\
\text { live births }\end{array}$} \\
\hline & $\begin{array}{l}\text { Intromission } \\
\text { frequency }\end{array}$ & $\begin{array}{l}\text { Ejaculation } \\
\text { frequency }\end{array}$ & $\begin{array}{c}\text { Seminal } \\
\text { vesicles } \\
\text { (mg) }\end{array}$ & $\begin{array}{l}\text { Ventral } \\
\text { prostate } \\
\text { gland } \\
(\mathrm{mg})\end{array}$ & $\begin{array}{l}\text { Bulbospongiosus } \\
\text { muscles } \\
\text { (mg) }\end{array}$ & \\
\hline I (No drug + TCI for $45 \mathrm{~min}$ ) & $41 \pm 5$ & $1.9 \pm 0.3$ & $34 \pm 2.0$ & $21 \pm 2$ & $27 \pm 1.0$ & $50 \%^{\mathrm{a}}$ \\
\hline 2 (Drug, no TCI) & $29 \pm 6$ & $2.1 \pm 0.4$ & $34 \pm 1.5$ & $19 \pm 2$ & $29 \pm 0.9$ & $0 \%{ }^{\mathrm{b}}$ \\
\hline 3 (Drug + TCI for $45 \mathrm{~min}$ ) & $29 \pm 7$ & $1.7 \pm 0.3$ & $35 \pm 0.9$ & $2 I \pm 2$ & $28 \pm 1.1$ & $10 \%^{\mathrm{b}}$ \\
\hline 4 (No drug, no clamp) & $34 \pm 9$ & $2.4 \pm 0.2$ & $37 \pm 1.1$ & $20 \pm 1$ & $27 \pm 1.0$ & $60 \%^{a}$ \\
\hline
\end{tabular}

Sexual performance was measured during pairings of a male with an intact, receptive female; the frequencies of intromissions and ejaculations were recorded (Taylor et al., 1989a).

Paternity was established by the delivery of live pups from female partners of the males tested. The percentage values in this column are the number of males per group that successfully impregnated a female in either of two mating sessions.

Androgen-sensitive structures (seminal vesicles, ventral prostate glands and bulbospongiosus muscles) were weighed 10 weeks after treatment (mg tissue per $100 \mathrm{~g}$ body mass).

Superscript letters indicate statistically reliable group differences (Tukey's HSD test; $P<0.05$ ).

Finally, all animals were killed at the end of behavioural testing. Seminal vesicles, bulbospongiosus muscles and ventral prostates were excised and wet masses obtained as markers of reproductive physiology. There were no differences between drug-exposed and control groups in any of these structures.

\section{Discussion}

Testicular circulatory isolation is a surgical technique designed to avert local damage to testicular function during exposure to a toxin (Farr et al., 1993). An animal model of TCI was used and two experiments were conducted to answer separate but related questions about acute and chronic consequences on reproductive competence following exposure to a common chemotherapeutic agent.

Chemical treatments (Ward et al., 1990; Parchuri et al., 1993; Kangasniemi et al, 1995b) or surgical occlusion (Stern et al., 1990; van Vliet et al., 1993) have been designed to spare fertility of males exposed to procarbazine and other toxic substances used in the treatment of cancer. Those studies used indirect measures, typically sperm head counts and testicular integrity, rather than the direct measurement of paternity in the form of live births. Nevertheless, the impression left by these studies is that there are protective techniques that allow full recovery to premorbid degrees of sexuality and fertility (Stern et al., 1990; Ward et al., 1990).

However, the present study used carefully controlled contacts with females and indirect and direct measures of fertility. Young adult male rats were exposed to procarbazine with or without concurrent clamping of the spermatic cord and gubernaculum for $15 \mathrm{~min}$ or $45 \mathrm{~min}$. Reproductive consequences were assessed using various paradigms for assessing sociosexual behaviour, androgen-sensitive tissue morphology and fertility of male rats (Taylor and Weiss, 1987; Barfield, 1993; Taylor et al., 1993). Treated males were compared with untreated controls to provide a more precise empirical test of the hypothesis that the TCI procedure would leave males with 'normal' reproductive capacity. In Expt 1, weekly behavioural tests were used to assess changes in sexual motivation and aggressiveness 3-10 weeks after surgery. In Expt 2, the study focused on copulatory performance and fertility 2 months after treatments.

The findings of Expt $I$ indicated that sexual motivation, or 'libido', was not disrupted in any of the procarbazine-treated groups relative to the controls. However, there was evidence of drug-induced suppression of aggressive behaviour in males administered procarbazine without TCI. There was no evidence of recovery of this function over time. Adverse effects on a male's aggressiveness could be observed within a few weeks of surgery, and that adverse effect remained stable for up to 10 weeks after treatment. Most notably, TCI for $45 \mathrm{~min}$ preserved the social behaviour studied of male rats receiving the procarbazine regimen. However, males receiving the drug with only 15 min of TCI, were more similar to the unprotected, drug-exposed group than to the other groups.

The findings of Expt 2 point directly to decreased male fertility with procarbazine. Paternity was reduced to a similar extent in all drug-exposed males. The presence or absence of $\mathrm{TCI}$ did not improve fertility but this reduced fertility was not a result of obvious impairments to copulation. Males in procarbazine-exposed groups, particularly the group exposed to the drug plus TCI for $45 \mathrm{~min}$, showed comparable sexual performance to animals from the control group with no drug treatment. In both experiments, there was no evidence for differences between groups in the integrity of seminal vesicles, bulbospongiosus muscles or ventral prostates. This suggests that any deleterious effects on fertility did not result from endocrine disruption to reproductive physiology. Similarly, clamping of the blood supply to the testis for up to $45 \mathrm{~min}$ had no lasting impact on any measure of sexual behaviour, physiology or fecundity. Results revealed no differences 
between groups not exposed to procarbazine but given TCI and control groups given no drug and no clamp.

The overall conclusion is that procarbazine causes no detectable change in the interest of a male rat for a receptive female nor in his copulatory effectiveness. However, the drug suppresses intermale aggressive behaviour and, perhaps more important, the capacity to impregnate a female. There was no recovery over time in animals experiencing impairment soon after the drug exposure, suggesting that losses in normal social behaviour and fertility are probably permanent. Previous work (Farr et al., 1993) points to failure of testicular spermatogenesis to recover fully as a likely source of the infertility in males exposed to procarbazine. The mechanism for the reduced aggressiveness in procarbazine-exposed animals is not obvious. It is unlikely to be based on androgens; androgen-sensitive sexual behaviour and secondary sex structures recovered normally in both drug and TCI groups. Certainly, the differences in aggressive behaviour suggest modification of the central nervous system. That aggressiveness and fertility of the group not exposed to procarbazine but given $\mathrm{TCl}$ for $45 \mathrm{~min}$ was equal to that of controls suggests full restoration of both peripheral and central functions.

Conclusions on the value of the $\mathrm{TCl}$ procedure are mixed. Although the procedure failed to prevent the infertility common with procarbazine, $\mathrm{TCl}$ reduced the impact of the drug on behaviour. Compared with drug-exposed males without TCI, procarbazine-exposed males given $45 \mathrm{~min}$ of TCI showed less disruption of responses to another male. Of clinical relevance is the confirmation from our animal findings of prior reports (Devlen et al., 1987) for men who have undergone chemotherapeutic treatments. The suggestion is that procarbazine will reduce their capacity to father children, even with attempts to block toxicity by using procedures such as TCI.

Nevertheless, the findings give reason for optimism. The data suggest that procarbazine-treated men might be expected to show rapid recovery of their capacity to initiate and complete mutually satisfying copulation. In addition, a notable finding was the safety of the $\mathrm{TCl}$ procedure, which did not produce dysfunction in behaviour, physiology or fertility.

The research was supported, in part, by grants from the Veterans Administration (to F. E. Johnson) and a UM-St Louis Research Award (to G. T. Taylor).

\section{References}

Barfield RJ (1993) Animal models of human sexual behaviour. In Sexual Pharmacology pp 73-86 Eds AJ Riley, M Peet and CA Wilson. Oxford Medical Publications, Oxford

Byrne J, Mulvihill JJ, Myers MH, Connelly R, Naughton M, Krauss M, Steinhorn S, Hassinger D, Austin D, Bragg K, Holmes G, Holmes F, Latourette H, Weyer R, Meigs J, Teta M, Cook J and Strong L (1987) Effects of treatment on fertility in long-term survivors of childhood or adolescent cancer New England Medical Journal 317 1315-1317

Clermont Y (1972) Kinetics of spermatogenesis in mammals: seminiferous epithelial cycle and spermatogonial renewal Physiological Reviews 52 $198-236$
Conrad ME and Crosby WH (1960) Massive nitrogen mustard therapy in Hodgkin's disease with protection of bone marrow by tourniquets Blood 16 1089-1103

Devlen J, Maguire P, Phillips P and Crowther D (1987) Psychological problems associated with diagnosis and treatment of lymphomas I. Retrospective study British Journal of Medicine 295 953-957

Grant EC (1963) An analysis of the social behaviours of the male laboratory rat Behaviour 21 260-281

Gregory RP, Cooke T, Middleton J, Buchanan RB and Williams CJ (1982) Prevention of doxorubicin-induced alopecia by scalp hypothermia: relation to degree of cooling British Medical Journal 284 1674-1675

Farr SA, Susman RS, Sunwoo YC and Johnson FE (1993) Regional procarbazine delivery reduces testicular toxicity Surgical Oncology 2 349-356

Kangasniemi M, Wilson G, Huhtaniemi I and Meistrich M (1995a) Protection against procarbazine-induced testicular damage by the $\mathrm{GnRH}$-agonist and antiandrogen treatment in the rat Endocrinology 136 3677-3680

Kangasniemi M, Wilson G, Parchuri N, Huhtaniemi I and Meistrich M (1995b) Rapid protection of rat spermatogenic stem cells against procarbazine by treatment with a gonadotropin-releasing hormone antagonist ( $\mathrm{Nal}-\mathrm{Glu}$ ) and an antiandrogen (flutamide) Endocrinology 136 2881-2888

Liebscher G, Tolman K, LaRegina M, Janney C and Johnson F (1990) Fertility preservation following doxorubicin therapy Surgical Forum 41 680-682

Parchuri N, Wilson G and Meistrich M (1993) Protection by gonadal steroid hormones against procarbazine-induced testicular damage to spermatogenic function in LBNFI hybrid rats Journal of Andrology 14 257-266

Rivkees SA and Crawford JD (1988) The relationship of gonadal activity and chemotherapy-induced gonadal damage Journal of American Medical Association $2592123-2125$

Sachs BD and Meisel RL (1994) The physiology of male reproductive behavior. In The Physiology of Reproduction (Vol. 2, 2nd Edn) pp 3-106 Eds E Knobil and JD Neill. Raven Press, New York

Schilsky RL, Lewis B, Sherins RJ and Young RC (1980) Gonadal dysfunction in patients receiving chemotherapy for cancer Annals International Medicine 93 109-114

Stern J, Lui R, LaRegina M, Herbold D, Tolman K and Johnson FE (1990) Long-term outcome following testicular ischemia in the rat journal of Andrology 4 390-395

Taylor GT and Weiss J (1987) Behaviour and fecundity of female rats mated with preferred and non-preferred males Animal Behaviour 35 115-121

Taylor GT, Haller J, Rupich R and Weiss J (1984) Testicular hormones and intermale aggressive behaviour in the presence of a female rat Journal of Endocrinology 100 315-321

Taylor GT, Bardgett ME, Griffin MG and Weiss J (1989a) Reproductive behavior and physiology of nulliparous female rats after sexual experience Behavioural Processes 19 31-46

Taylor GT, Komitowski D, Muto S and Weiss J (1989b) Behavioral endocrinology of male rats with periodic sexual contacts with exclusive or varied females Proceedings of the Society of Experimental Biology and Medicine 192 236-24I

Taylor GT, Bardgett M, Farr S, Womack S, Komitowski D and Weiss J (1993) Steroidal interactions in the ageing endocrine system: absence of suppression and pathology in reproductive systems of old males from a mixed-sex, socially stressful rat colony Journal of Endocrinology 137 115-122

Taylor GT, Scherrer J, Weiss J and Pitha J (1994) Endocrine interactions: adrenal steroids and precursors American Journal of Physiology 266 E676-E681

Taylor G, Bardgett M, Csernansky J, Early T, Haller J, Scherrer J and Womack S (1996) Serotonin, fluoxetine and male rat reproductive systems Physiology and Behavior 59 200-210

van Vliet J, Bootsma A, van Peperzeel H, Schipper J and Wensing C (1988) Protective effect of hypoxia in the ram testis during single and split-dose X-irradiation Radiotherapy and Oncology 13 9-16

van Vliet J, Dijkstra G, deRooij D, Wensing C and Bootsma A (1993) Repeated interruptions of the testicular blood flow do not have long-term effects on spermatogenesis in the ram Andrologia 25 245-249

Ward J, Robinson J, Furr B, Shalet S and Morris I (1990) Protection of spermatogenesis in rats from the cytotoxic procarbazine by the depot formulation of Zoladex, a gonadotropin-releasing hormone agonist Cancer Research 50 568-574 